\author{
А.А. Антошкин ${ }^{1}$, П.А. Качанов ${ }^{2}$, В.И. Галица ${ }^{2}$, А.Н. Литвяк ${ }^{1}$ \\ ${ }^{1}$ Национальный университет гражданской защчиты Украины, Харьков \\ ${ }^{2}$ Национальный технический университет «ХПИ», Харьков
}

\title{
ИССЛЕДОВАНИЕ ВЛИЯНИЯ ЭЛЕКТРОСТАТИЧЕСКОГО ПОЛЯ НА СКОРОСТЬ ОСАЖДЕНИЯ МЕЛКОДИСПЕРСНОЙ ПЫЛИ
}

\begin{abstract}
Проведены экспериментальные исследования влияния электростатического поля на скорость осаждения мелкодисперсной пыли, полученной при сжигании огнетушащего аэрозоля. Полученные результаты показывают, что для принятых условий эксперимента скорость осаждения аэрозолеобразуюших составов увеличивается примерно в 1,7 раза, по сравнению с гравитачионным способом. Выявлено, что наиболее интенсивно пыль оседает на электростатических пластинах в областях завихрений, образованными входной решеткой. Падение скорости осаждения огнетушащего аэрозоля на пластинах связано с загрязнением выходной решетки ГВ-1.
\end{abstract}

Ключевые слова: электростатическое поле, мелкодисперсная пыль, запыленная среда, огнетушаший аэрозоль, скорость осаждения аэрозоля.

\section{Введение}

Постановка проблемы. Вредное воздействие на здоровье человека промышленной пыли до сих пор является серьезной проблемой. Особенно сложной задачей является очистка воздуха от мелкодисперсной пыли, когда обыкновенная фильтрация воздуха оказывается недостаточно эффективной.

К современным средствам пожаротушения относятся генераторы огнетушащего аэрозоля ГОА при срабатывании которых выделяется мелкодисперсный аэрозоль, являющийся эффективным средством тушения пожаров любого класса. Однако после срабатывания генератора огнетушащего аэрозоля атмосфера в помещении долгое время остается непригодной для дыхания. Принимая во внимание жесткие требования [1] по степени негерметичности помещений, защищаемых аэрозольными установками пожаротушения, восстановление нормальных условий проветриванием занимает слишком много времени. Использование дымососов для удаления огнетушащего аэрозоля (ОА) потребует установки на них фильтров для предотвращения выброса мелкодисперсной взвеси в атмосферу и оседания ее на прилежащей территории.

Таким образом, существует проблема исследования способов увеличения скорости осаждения частиц аэрозоля в замкнутых объемах. Проблема становится еще более актуальной для случаев, когда проветривание объемов вообще невозможно.

Анализ последних исследований и публикаций. Для очистки воздуха от пыли на производственных предприятиях применяют, как правило, механические фильтры. При таком способе очистки наиболее опасные мелкодисперсные частицы остаются в воздухе. Для их осаждения необходимо применение других, более эффективных способов: аку- стическое и ультразвуковое воздействие [2], воздействие электростатическим полем [3], распыление электростатических частиц [4].

При исследовании горения аэрозолеобразующих составов (АОС) основное внимание уделялось определению избыточного давления в помещении и решению проблемы высокой температуры сгорания АОС $[5,6]$. Вопросы же осаждения ОА исследовались лишь с использованием гравитационного метода [6]. Исследований влияния электростатического поля на скорость осаждения ОА не проводилось. Таким образом исследование способов увеличения скорости осаждения ОА до сих пор остается проблемой.

\section{Постановка задачи и ее решение}

Задачей данной работы является исследование влияния электростатического поля на скорость осаждения ОА. В качестве объекта исследования был выбран замкнутый объем высотой 485 мм, шириной 460 мм и длинной 500 мм. В этом объеме сжигались аэрозолеобразующие заряды E-1 разной массы и создавалась различная концентрация ОА.

Для исследования влияния электростатического поля на скорость осаждения ОА внутрь объекта был помещен разработанный электростатический прибор ГВ-1 (рис. 1) с электростатическими пластинами общей площадью $12032 \mathrm{Mm}^{2}$, на которые подавалось напряжение $20 \kappa \mathrm{V}$.

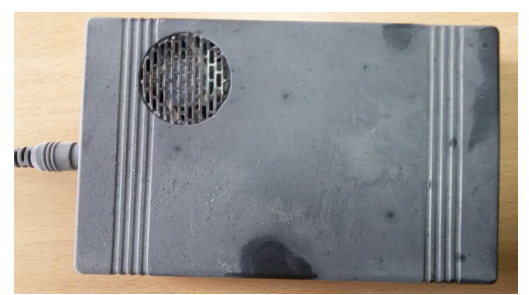

Рис. 1. Электростатический прибор ГВ-1 
Через пластины прокачивалась газовоздушная среда с начальной скоростью $2 \mathrm{M} / \mathrm{c}$, через выходное отверстие площадью 500мм². Схема экспериментальной установки показана на рис. 2.

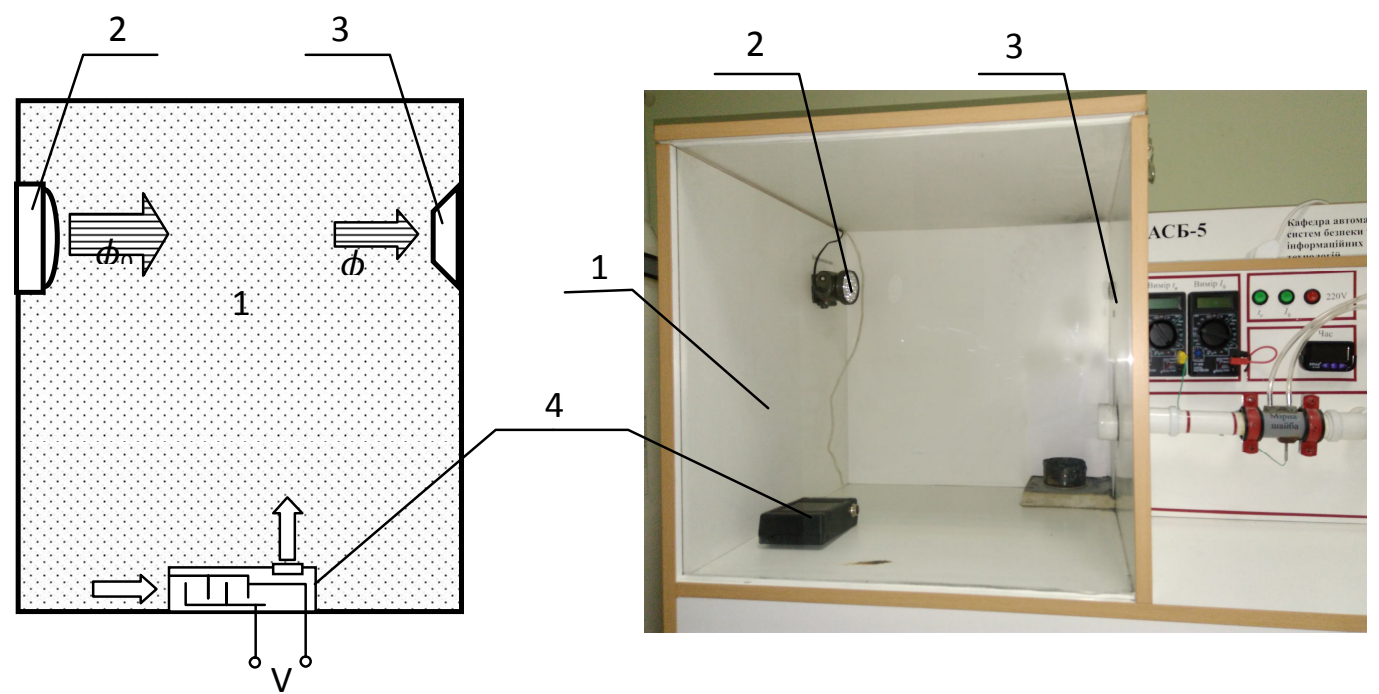

Рис. 2. Схема экспериментальной установки: 1 - модель помещения; 2 - источник света;

3 - фотоэлектрический приемник (Ленинград-4); 4 - электростатический воздухоочиститель ГВ-1

Изменение концентрации ОА исследовалось оптическим методом. Согласно закону ЛамбертаБера:

$$
\varphi=\varphi_{0} \cdot \mathrm{e}^{-\mathrm{kc}_{\mathrm{a}} \mathrm{l}}
$$

где $\phi_{0}=420, \mathrm{MV}-$ эквивалент интенсивности светового потока излучателя в прозрачной среде; $\phi-$ эквивалент интенсивности светового потока в запыленной среде, мV; k - коэффициент, учитывающий оптические свойства газовоздушной среды; с a $_{-}$ концентрация взвешенных частиц; 1 - расстояние между излучателем и приемником.

Как видно, концентрация аэрозоля однозначно связана с интенсивностью светового потока проникающего через запыленную среду.

Для удобства анализа результатов использовалось понятие относительной оптической плотности среды:

$$
\mathrm{S}_{\mathrm{x}}=\frac{\phi_{0}-\phi}{\phi_{0}}
$$

После сжигания АОС показания ФЭП фиксировались с шагом 1 минута. Первые 10 мин осаждение ОА происходило под действием гравитации, Последующие 10 мин осаждение ОА происходило с использованием электростатического прибора ГВ-1.

Было запланировано проведение 4-х экспериментов:

Эксперимент 1: масса аэрозоля 2,5 г.

Эксперимент 2 : масса аэрозоля 1,5 г.

Эксперимент 3 : масса аэрозоля 2.0 г.

Эксперимент 4 : масса аэрозоля 1.0 г.

Протокол эксперимента представлен в табл. 1.

Изменение оптической плотности газовоздушной среды показано на рис. 3 .
Таблица 1

Протокол эксперимента

\begin{tabular}{|c|c|c|c|c|c|c|c|c|}
\hline $\begin{array}{c}\mathrm{t}, \\
\text { мин }\end{array}$ & $\begin{array}{c}\varphi_{1}, \\
\mathrm{mV}\end{array}$ & $\mathrm{Sx}_{1}$ & $\begin{array}{c}\varphi_{2}, \\
\mathrm{mV}\end{array}$ & $\mathrm{Sx}_{2}$ & $\begin{array}{c}\varphi_{3}, \\
\mathrm{mV}\end{array}$ & $\mathrm{Sx}_{3}$ & $\begin{array}{c}\varphi_{4}, \\
\mathrm{mV}\end{array}$ & $\mathrm{Sx}_{4}$ \\
\hline 0 & 306 & 27,1 & 297 & 29,3 & 299 & 28,8 & 313 & 25,5 \\
\hline 1 & 306 & 27,1 & 309 & 26,4 & 310 & 26,2 & 317 & 24,5 \\
\hline 2 & 308 & 26,7 & 311 & 26,0 & 314 & 25,2 & 318 & 24,3 \\
\hline 3 & 310 & 26,2 & 317 & 24,5 & 316 & 24,8 & 328 & 21,9 \\
\hline 4 & 316 & 24,8 & 321 & 23,6 & 321 & 23,6 & 330 & 21,4 \\
\hline 5 & 319 & 24,0 & 325 & 22,6 & 325 & 22,6 & 333 & 20,7 \\
\hline 6 & 323 & 23,1 & 328 & 21,9 & 329 & 21,7 & 336 & 20,0 \\
\hline 7 & 326 & 22,4 & 331 & 21,2 & 333 & 20,7 & 342 & 18,6 \\
\hline 8 & 330 & 21,4 & 335 & 20,2 & 337 & 19,8 & 343 & 18,3 \\
\hline 9 & 335 & 20,2 & 340 & 19,0 & 341 & 18,8 & 345 & 17,9 \\
\hline $\mathbf{1 0}$ & $\mathbf{3 4 3}$ & $\mathbf{1 8 , 3}$ & $\mathbf{3 4 5}$ & $\mathbf{1 7 , 9}$ & $\mathbf{3 4 5}$ & $\mathbf{1 7 , 9}$ & $\mathbf{3 4 9}$ & $\mathbf{1 6 , 9}$ \\
\hline $\mathbf{1 1}$ & $\mathbf{3 4 9}$ & $\mathbf{1 6 , 9}$ & $\mathbf{3 5 8}$ & $\mathbf{1 4 , 8}$ & $\mathbf{3 5 7}$ & $\mathbf{1 5 , 0}$ & $\mathbf{3 6 0}$ & $\mathbf{1 4 , 3}$ \\
\hline $\mathbf{1 2}$ & $\mathbf{3 5 8}$ & $\mathbf{1 4 , 8}$ & $\mathbf{3 6 4}$ & $\mathbf{1 3 , 3}$ & $\mathbf{3 6 3}$ & $\mathbf{1 3 , 6}$ & $\mathbf{3 6 6}$ & $\mathbf{1 2 , 9}$ \\
\hline $\mathbf{1 3}$ & $\mathbf{3 6 7}$ & $\mathbf{1 2 , 6}$ & $\mathbf{3 7 2}$ & $\mathbf{1 1 , 4}$ & $\mathbf{3 6 9}$ & $\mathbf{1 2 , 1}$ & $\mathbf{3 7 1}$ & $\mathbf{1 1 , 7}$ \\
\hline $\mathbf{1 4}$ & $\mathbf{3 7 3}$ & $\mathbf{1 1 , 2}$ & $\mathbf{3 7 9}$ & $\mathbf{9 , 8}$ & $\mathbf{3 7 5}$ & $\mathbf{1 0 , 7}$ & $\mathbf{3 7 7}$ & $\mathbf{1 0 , 2}$ \\
\hline $\mathbf{1 5}$ & $\mathbf{3 7 9}$ & $\mathbf{9 , 8}$ & $\mathbf{3 8 4}$ & $\mathbf{8 , 6}$ & $\mathbf{3 7 9}$ & $\mathbf{9 , 8}$ & $\mathbf{3 8 3}$ & $\mathbf{8 , 8}$ \\
\hline $\mathbf{1 6}$ & $\mathbf{3 8 4}$ & $\mathbf{8 , 6}$ & $\mathbf{3 8 8}$ & $\mathbf{7 , 6}$ & $\mathbf{3 9 3}$ & $\mathbf{6 , 4}$ & $\mathbf{3 8 8}$ & $\mathbf{7 , 6}$ \\
\hline $\mathbf{1 7}$ & $\mathbf{3 8 8}$ & $\mathbf{7 , 6}$ & $\mathbf{3 9 2}$ & $\mathbf{6 , 7}$ & $\mathbf{3 8 7}$ & $\mathbf{7 , 9}$ & $\mathbf{3 9 1}$ & $\mathbf{6 , 9}$ \\
\hline $\mathbf{1 8}$ & $\mathbf{3 9 2}$ & $\mathbf{6 , 7}$ & $\mathbf{3 9 5}$ & $\mathbf{6 , 0}$ & $\mathbf{3 9 0}$ & $\mathbf{7 , 1}$ & $\mathbf{3 9 4}$ & $\mathbf{6 , 2}$ \\
\hline $\mathbf{1 9}$ & $\mathbf{3 9 5}$ & $\mathbf{6 , 0}$ & $\mathbf{3 9 8}$ & $\mathbf{5 , 2}$ & $\mathbf{3 9 8}$ & $\mathbf{5 , 2}$ & $\mathbf{3 9 7}$ & $\mathbf{5 , 5}$ \\
\hline $\mathbf{2 0}$ & $\mathbf{3 9 7}$ & $\mathbf{5 , 5}$ & $\mathbf{4 0 0}$ & $\mathbf{4 , 8}$ & $\mathbf{4 0 0}$ & $\mathbf{4 , 8}$ & $\mathbf{4 0 0}$ & $\mathbf{4 , 8}$ \\
\hline & & & & & & & & \\
\hline
\end{tabular}

\section{Выводы}

Полученные результаты показывают, что для принятых условий эксперимента скорость осаждения АОС увеличивается примерно в 1,7 раза, по сравнению с гравитационным способом. Выявлено, что наиболее интенсивно пыль оседает на электростатических пластинах в областях завихрений, образованными входной решеткой. Падение скорости осаждения ОА на пластинах связано с загрязнением выходной решетки ГВ-1. 


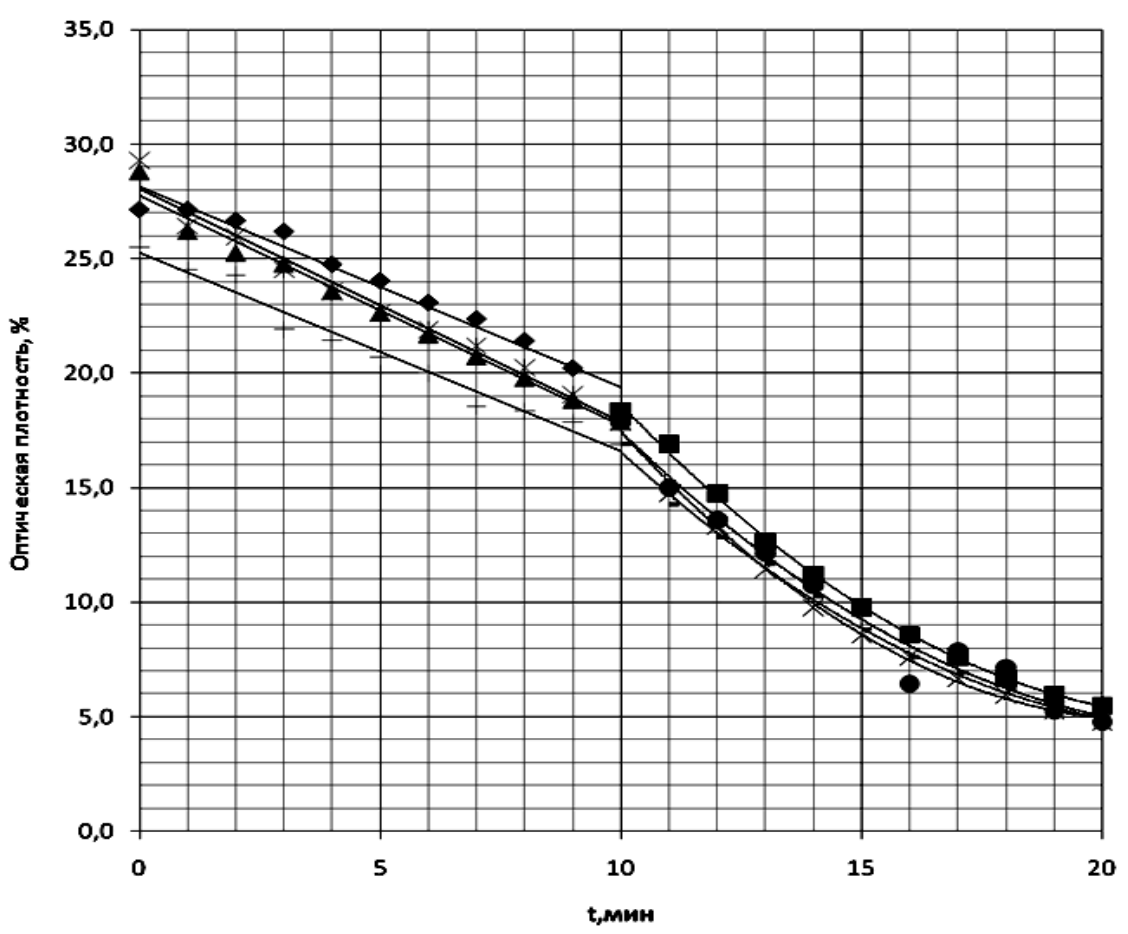

Рис. 3. Изменение оптической плотности среды

\section{Список литературы}

1. Пожежна техніка. Установки автоматичні аерозольного пожежогасіння. Проектування, монтування та експлуатування: ДСТУ 4490:2005 - [Чинний від 200525-11]. - К. : Держспожсивстандарт України.-2005.- 16 c. (Національний стандарт Украӥни).

2. Антонникова, А.А., Коровина Н.В., Кудрямова О.Б. Ультразвуковое осаждение мелкодисперсного аэрозоля // Известия ТПУ. - 2014. - T.324. - №2. - c.57-62.

3. Степкина М.Ю., Ахмадеев И.Р., Ворожиов Б.И. Экспериментальное исследование способа ускорения мелкодисперсного аэрозольного облака под действием электростатического поля // Ползуновский вестник. - 2014. №3. - c. 134-138.

4. Olga Kudryashova and Maria Stepkina Electrostatic charge of power particles and their sorption capacity // Proc. HEMS 2016? 136-137, Tomsk (2016).
5. Бондаренко С.Н. Применение генераторов огнетушамего аэрозоля в составе автоматических установок пожаротушения, вопросы математического моделирования/ С.Н. Бондаренко // Проблемы пожарной безопасности.- 1999. - №3.- С. 25-28. - Режим доступу: http://repositsc.nuczu.edu.ua/handle/123456789/1512.

6. Литвяк А.Н Экспериментальное определение температуры и избыточного давления при работе генераторов огнетушащего аэрозоля. / А.Н. Литвяк, М.Н. Мурин // Проблемы пожарной безопасности. - Харьков, УГЗУ, - 2008. - Bып 24. - C.115-119. Режим доступу: http://repositsc.nuczu.edu.ua/bitstream/123456789/492/1/08\% 20Litvyak\%20Murin\%20GOA.pdf

Надійшла до редколегії 5.02.2018

Рецензент: д-р техн. наук, проф. М.I. Адаменко, Харківський національний університет ім. В.Н. Каразіна, Харків.

\section{ЕКСПЕРИМЕНТАЛЬНЕ ДОСЛІДЖЕННЯ ВПЛИВУ ЕЛЕКТРОСТАТИЧНОГО ПОЛЯ НА ШВИДКІСТЬ ОСАДЖЕННЯ ВОГНЕГАСНОГО АЕРОЗОЛЮ}

О.А. Антошкін, П.О.Качанов, В.І. Галиця, О.М. Литвяк

Проведено експериментальні дослідження впливу електростатичного поля на швидкість осадження дрібнодисперсного пилу, отриманої при спалюванні вогнегасної аерозолю. Отримані результати показують, що для прийнятих умов експерименту швидкість осадження аерозолеутворюючого складів збільшується приблизно в 1,7 рази, в порівнянні $з$ гравітаційним способом. Виявлено, щчо найбільш інтенсивно пил осідає на електростатичних пластинах в областях завихрень, освіченими вхідний гратами. Падіння швидкості осадження вогнегасної аерозолю на пластинах пов'язано $з$ забрудненням вихідний решітки ГВ-1.

Ключові слова: електростатичне поле, дрібнодисперсний пил, запилена среда, огнетушаший аерозоль, швидкість осадження аерозолю.

\section{INVESTIGATION OF THE INFLUENCE OF THE ELECTROSTATIC FIELD ON THE DEPOSITION RATE OF FINE DUST}

O.A. Antoshkin, P.A. Kachanov, V.I. Galitsa, A.N. Litvyak

Experimental studies of the influence of the electrostatic field on the deposition rate of fine dust obtained by burning a fire extinguishing aerosol. The obtained results show that, for the experimental conditions adopted, the sedimentation rate of the aerosol-forming compositions increases approximately by 1.7 times, in comparison with the gravitational method. It was found that the dust is most intensely deposited on electrostatic plates in the vortex regions formed by the input grating. The drop in the speed of deposition of the extinguishing aerosol on the plates is associated with the contamination of the output grating $\Gamma B-1$.

Keywords: electrostatic field, fine dust, dusty environment, fire extinguishing aerosol, aerosol deposition rate. 